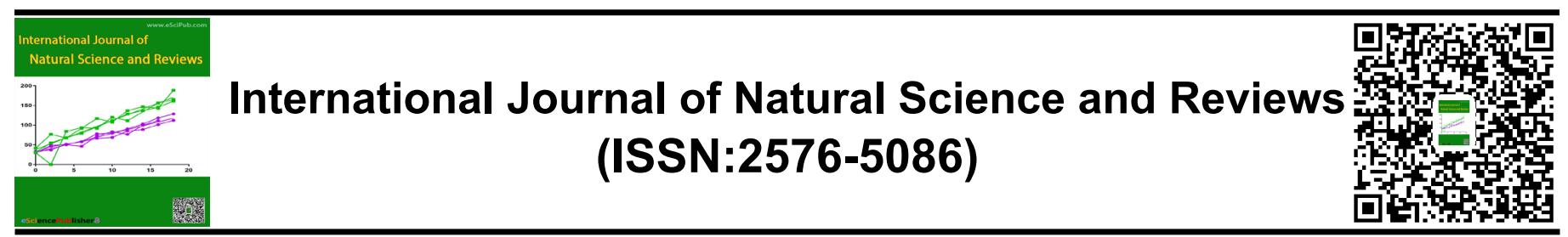

\title{
Electric Vehicle Intelligent Service Cloud Platform
}

\author{
Peijun Jiang', Yiqian Gao', Ao Luo ${ }^{1}$
}

${ }^{1}$ School of Electrical and New Energy, China Three Gorges University 43002, China.

\begin{abstract}
In recent years, electric vehicles have developed rapidly around the world. A series of research and services for electric vehicles are also rapidly developing. Faced with the broad market demand, Yichang Ju Calling Company launched the intelligent charging and switching service cloud platform "Gathering".

*Correspondence to Author:

Lv Jianxing

School of Electrical and New Ener-

Based on technologies such as Internet of Things, Internet, and big data analysis, the solution builds an intelligent vehicle cloud platform for electric vehicles. The intelligent cloud platform has an electric vehicle charging and reloading reservation, a next destination navigation charging and switching plan, and a private charging pile sharing. Charging pile inquiry and reservation, fee settlement, user community communication and other functions make the electric vehicle charging service platform more intelligent and convenient. At the same time, as a bridge between electric vehicles and charging stations, "Gathering" can combine the real-time electricity price, the degree of traffic congestion, the use of charging piles and the load of the power grid to plan more efficient and convenient charging suggestions for users. Make full use of power resources to reduce the load and cost of the grid.

gy, China Three Gorges University 43002, China.

How to cite this article:

Peijun Jiang, Yiqian Gao, Ao Luo. Electric Vehicle Intelligent Service Cloud Platform. International Journal of Natural Science and Reviews, 2019; 4:10.

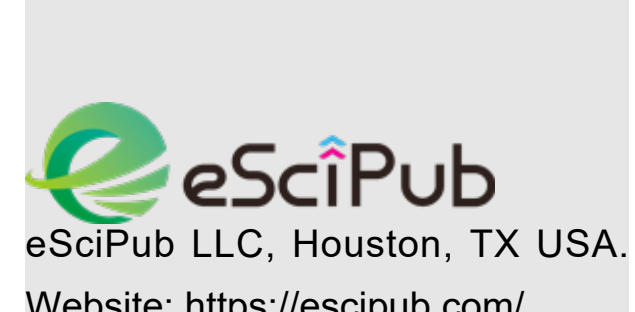

Keywords: Electric vehicle; Charging pile; Internet of things intelligent service
\end{abstract}




\section{Background introduction}

With the development of the national new energy strategy, the electric vehicle market has developed tremendously and the number of new energy vehicles has increased dramatically. This also brings a series of problems:

I. In terms of the construction of charging facilities for new energy vehicles, China has been in a backward state for a long time. The imbalance between the promotion of new energy vehicles and the construction of charging facilities has not changed much. The number of private charging piles has increased greatly, and the pileto-pile ratio is close to $4: 1$. The overall situation of charging difficulty has not changed fundamentally. The contradiction between charging $d$ ifficulty and low utilization rate of charging facilities is still outstanding.

Second, the current charging navigation products on the market require the user to manually search for a charging station when the electric vehicle is low, and need to go to the charging station specifically for charging, that is, the user time is consumed, and the charging station position is often difficult to find. Charging is very inconvenient.

Third, the existing charging piles are operated independently for each platform. In recent years, due to the high construction cost of charging piles, the various platforms cannot be universally affected and the development of electric vehicle charging services has been affected. Most electric vehicle charging pile manufacturers are at Loss status.

Fourth, the number of private charging piles has increased significantly. However, the construction cost of private charging piles is high, and it is difficult for individual charging users to bear, and the charging cost is high, and private charging piles are not fully utilized.
And now is the era of the Internet + wave.

The Internet can inject new vitality into reform and opening up. First, the Internet has injected new vitality into efficiency through asset reuse. Different from the common use in the early stage of reform and opening up, the contemporary sharing economy is developed according to the Internet. The biggest difference is that the data can be copied at zero cost, and the information assets and data production materials can be retained under the control of the right. The right to use these means of production in a platform $\mathrm{m}$ anner, according to the use of laborers, from the laborer's income to pay a certain consideration to all. Workers can intervene in capital operations and create wealth simply by virtue of their right to use and without the need for control. Through the sharing of basic business and value-added services, we will expand high-end consumer demand, improve user experience, further release consumption potential, make full use of social governance, and effectively protect consumer rights. Second, the Internet has injected new vitality into reform and opening up by raising the fairness of distribution. By sharing and using, the whole people can enjoy the fairness that they did not enjoy in one distribution. Therefore, sharing is no longer just through secondary distribution, transfer payment, sharing only development achievements, but sharing development opportunities.

In 2017, the global mobile phone usage was 9.17 billion units, of which 5.56 billion were smartphones. It is estimated that by 2023 , the global mobile phone usage will reach 10.72 billion units, of which 8.83 billion are smartphones. The initial explosive growth of smartphones came from the replacement of functional machines. The most essential difference between a smartphone and a function machine is the rich APP 
resources, which makes the mobile phone become a social carrier-centric function carrier beyond single call and text message, which becomes the core power of the first wave of the smart phone replacement function machine.

\section{Development status}

The State Council officially announced the development plan for energy-saving and new-energy automobile industry (2012-2020), and the objectives of various industrial policies and the industrial development route have gradually become clear. In the future, pure electric drive will be the main strategic orientation for the development of new energy vehicles.

According to the official data released by the China Charging Union, as of May 2018, the member units in the alliance reported a total of 266,231 public-charged piles, and the member cars of the alliance sampled the piles with the information data of 441,422 , totaling about 70.8 . Ten thousand.

In terms of public charging piles, there are 116761 AC charging piles, 84174 DC charging piles, and 65296 AC-DC integrated charging piles. In May 2018, 4,173 public-type charging piles were added than in April 2018. From May 2017 to April 2018, about 8,273 public-type charging piles were added every month, and in May 2018 , the growth rate was $59.5 \%$.

The number of large-scale operators in the country reached 16 (the number of charging facilities $>=1000$ ), and the special potential was the first. 110,857 charging piles were built, followed by the State Grid and 56,549 charging piles.

A survey was conducted nationwide to conduct a survey. The ratio of male to female surveyed was 1:1. According to statistics, it is known that a new generation of young people is willing to purchase electric vehicles. With the upgrading of production capacity, traditional energy sourc- es are increasingly exhausted. It is widely believed that renewable energy will be widely used, and the development prospects of electric vehicles are generally optimistic. .

\section{Current problems in the electric vehicle charging pile service industry}

\section{1 poor user experience}

At the same time as the rapid development of the electric vehicle market, problems have gradually emerged. For example, many investment institutions have entered the market, but the industry standards are not uniform, and users are not convenient enough when using charging piles. There are currently several similarly positioned products. Since the resources of each merchant cannot be well integrated, the user cannot conveniently query the nearby charging pile or the power station, and the payment method is not uniform. As a result, the user experience of the existing electric vehicle service industry is not good and needs to be solved urgently.

\section{2 low utilization}

According to the data disclosed by the Energy Bureau, as of the end of 2017, China's various types of charging piles reached 450,000 , and the number of public charging piles was 210 , 000 . The number of holdings ranked first in the world. Although the current construction volume is large, the current public charging pile utilization rate Less than $15 \%$, due to unreasonable layout, maintenance is not in place, and there are many faults and zombie piles in some areas. The low utilization rate of charging piles has become a prominent problem that restricts the development of the charging industry. The person in charge of the public charging pile company said that at present, in many cities, the utilization ratio of public charging piles in different regions shows a polarization difference. In 
the same city, the utilization rate of some areas can reach $70 \%$, but some areas are extremely low.

First of all, due to the large number of pile pile production enterprises, the pile charging interface, especially the incompatibility of the DC interface, still exists, and the level of interoperability of the operator platform is relatively low. Secondly, the number of new energy vehicles is relatively small. Most users are self-owned charging piles. The average utilization rate of public charging piles is less than $15 \%$. The industry's profitability is relatively low. The business model needs further exploration. However, due to unreasonable layout and inadequate maintenance, there have been many faults and zombie piles in some areas. In addition, the charging interface security standards have yet to be improved, charging information and payment are also facing some risks of network security vulnerabilities.

\section{4. project overview}

The solution is based on the improvement of the new energy vehicle service ecosystem small program, users can easily obtain the real-time dynamics of each charging station, and can formulate the optimal charging strategy according to the user's next destination travel plan and the remaining power of the user's electric vehicle. It can effectively perform reservation charging, battery replacement, etc., and can also exchange service experience through the user communication circle. Integrate the resources of various charging station investors to form an Internet-based electric vehicle service circle, which will benefit and benefit from it.

In-depth investigation, establish a regional database, find the key points and breakthroughs of development through market analysis, analyze regional differences, formulate effective strate- gies and improve implementation plans. Services and transactions through Internet platforms such as APP web pages. Develop and establish a coverage area terminal network to build a regional marketing value chain.

\section{Equipment requirements}

Yichang Ju Call Network Technology Co., Ltd. is committed to providing high-quality services to meet the requirements of different customers and achieve international leading level. To this end, through the various requirements of customers, improve the equipment and complete the user's requirements for the equipment.

\section{Equipment advantages}

With the current overall market environment of the electric vehicle service industry, electric vehicles have not been widely popularized in China, significantly improving the company's ability to participate in market competition and resist risks:

First, the company has an advantageous negotiating position in equipment procurement, which is relatively conducive to control and reduce production costs;

Second, the company invests a lot of strength in researching key technologies of products and providing comprehensive technical services and technical support to customers;

Third, the company's research and development, production, sales, management and after-sales service and other aspects of high synergy, has a clear advantage in quickly meeting customer needs;

Fourth, the marketing approach gives the company the strength and ability to adapt to the rapid changes in the market.

\section{Main functions}

(1) Inquiring and charging station nearby: Help users to check the surrounding charging station or charging pile, and know in real time whether it 
Peijun Jiang et al., IJNSR, 2019; 4:10

is the occupancy of charging piles or the number of remaining batteries in each charging station. According to the status of the charging station or the charging pile, the user can formulate a charging and replacing solution and plan the route reasonably.

(2) Next destination trip planning navigation: Based on the user's next destination trip and the remaining power of the electric vehicle, the user develops a convenient charging strategy. This eliminates the need for the user to spend time looking for a charging post, taking into account the factors that will be charged during the trip. Guide users to the most convenient and timesaving charging strategy.

(3) Charge and replacement appointments: help users to obtain real-time dynamic information of nearby charging stations, reserve fast charging or car replacement battery service in advance, and solve the problem that the owner arrives at the charging and replacing station and finds that there is no charging space or no available battery; the user can pass Alipay, WeChat payment or online banking and other fast payment methods are convenient to complete the payment, and the completion of the transaction can accumulate points for redemption of coupons or small gifts.

(4) Real-time understanding of the charging status: The APP client monitors the charging information in real time, and the user can understand the charging progress and receive the corresponding reminder in order to arrange the time reasonably. Respond to the user in case of accident or abnormal charging.

(5) Private charging pile sharing: Users with private charging piles can share their own charging piles on the "Gathering" platform, rent them to other users, and collect certain profits.

\section{Product competitiveness}

Technical advantages: At present, the electric vehicle charging platform on the market only has the function of querying nearby charging stations, and the function is too single and not intelligent enough. The company's "Gathering" software can not only query the number of nearby charging stations, display the number of available charging stations, and reserve the charging station for the user according to the estimated arrival time of the user. It is also possible to plan the travel route and the charging and replacing strategy for the user according to the real-time remaining power of the charging car and the next destination route of the user. Industry resource advantage: The popularity of electric vehicles is an important part of the national new energy strategy. We will integrate the charging and replacement resources of each power station and replace the power station companies, and provide a platform for each electric vehicle product company to interact with customers. Providing online charging and matching services is a high value-added industry that has accompanied the rise of traditional automobile manufacturing and service industries. Service specialization, refinement, and modernization are more in line with the development requirements of the Internet era and move toward high-quality life.

Advantages of the platform: The company's "Gathering" software is a small program of the basic WeChat platform, online booking charging pile, online payment, offline experience, in line with the development trend of "Internet +" under the information economy, on WeChat client It's easy to use, it doesn't take up the phone's memory, and it doesn't need to be downloaded in advance. We can also use the WeChat payment to realize the payment function, which greatly improves the efficiency. 
Peijun Jiang et al., IJNSR, 2019; 4:10

\section{Product Research and Development}

"Gathering" is a software developed based on the WeChat platform applet, and the WeChat applet has been popular with the public for its convenience in the past two years. WeChat is also a large social platform. Basically everyone has WeChat, so don't worry about their audience and promotion issues. Considering that "Gathering" is a service-oriented software, the number, convenience and promotion of users is a key factor. Therefore, the WeChat platform is currently the best development platform. Combined with WeChat's map navigation, real-time positioning, WeChat and confidential payment technology, our products are more efficient.

\section{Project Prospects}

The goal of China's charging infrastructure development is to build 12,000 centralized power stations and 4.8 million distributed charging piles by 2020 to meet the charging requirements of 5 million electric vehicles nationwide. It is also required that $100 \%$ of the newly built residential parking spaces should be built with charging infrastructure or reserved for construction and installation conditions. The parking lot for large $p$ ublic buildings, the charging infrastructure for social public parking lots, or the parking space reserved for construction and installation conditions are not low. At $10 \%$, at least one public charging station should be built for every 2,000 electric vehicles.

With the support of favorable policies in the past few years, the basic service facilities for electric vehicles are rapidly building, which has also brought huge demand for the electric vehicle service industry. At present, the popularity of smart phones in China is high, and people are also more It tends to handle transactions through mobile phones, so the electric car service mobile app will be favored by the market. There are several similar types of products on the market, but they are limited to a small number of areas, and they do not integrate the resources of various charging and replacing stations. There are many inconveniences in use. In general, the electric vehicle service industry still has In the early stages.

The target customer is the owner of the electric vehicle, and the charging and replacing service of the electric vehicle is taken as the main service. In the fast-developing electric vehicle industry in the future, it will provide convenient and high-quality electric vehicle services for car owners.

Charging and charging is a high-viscosity demand. Compared with other post-market service formats, the frequency of contact between the owner and the charging station is high, which means that it is more likely to generate user behavior data than other formats, and it is easier to establish other derivative service platforms. Form a diversified business model.

\section{1. project highlights}

(1) Service innovation. Traditional energy is increasingly exhausted, the production capacity structure is further upgraded, and renewable energy is gradually being widely used. At present, electric vehicles are in the early stage of popularization, and the electric vehicle supporting service industry has huge room for improvement. Breaking the traditional service concept, combining the characteristics of the Internet era, adopting the business model of online consumption and offline services, bringing convenience to users.

(2) National electric vehicle industry support. The state has issued a series of policies to support the development of electric vehicles and improve the construction of electric vehicle infrastructure. For example, the General Office of 
Peijun Jiang et al., IJNSR, 2019; 4:10

the State Council "Guiding Opinions on Accelerating the Construction of Electric Vehicle Charging Infrastructure" (Guo Ban Fa [2015] No. 73), National Development and Reform Commission and other four departments, "Guidelines for the Development of Electric Vehicle Charging Infrastructure (2015-2020) (Development and Reform Energy [2015] No. 1454), the Ministry of Finance's "Notice on the "13th Five-Year Plan" New Energy Vehicle Charging Infrastructure Reward Policy and Strengthening the Promotion and Application of New Energy Vehicles" (Cai Jian [2016] No. 7). It can be seen that the electric vehicle industry has received strong support from the state, and the prospects for the electric vehicle industry are promising.

(3) Conform to the development trend of "Internet + " under the information economy. The company's products "filling" with mobile phone app as the carrier, using 020 business model, online booking charging pile, online payment, offline experience, and effectively facilitate the travel of the public. Breaking the traditional offline consumption and offline service business model, it is in line with the development trend of "Internet + " under the information economy.

(4) Project operating costs are low. "Low cost, big spread" is a major feature of Internet thinking. The low operating cost is mainly reflected in the lack of time and geographical restrictions. The two-way communication feedback is rapid, the transmission speed is fast, and the scope is wide, thus reducing the marketing cost of the company; the direct selling function of the Internet reduces the store rent and inventory cost. There is also no need to hire a large number of staff like the traditional service industry, so this reduces labor costs. The company uses the mobile phone app as a carrier to provide online electric vehicle charging and matching services.
It uses Internet thinking to effectively reduce its operating costs.

(5) The added value of project services is high. Providing online charging and matching services is a high value-added industry that has accompanied the rise of traditional automobile manufacturing and service industries. Service specialization, refinement, modernization, and more in line with the development requirements of the Internet era, the mobile phone software "gathering" enables the public to quickly and effectively obtain the real-time dynamics of each charging station, online charging, battery replacement, etc. It is difficult to change the queue, find the difficulty of charging and replacing the electric pile nearby, and understand the difficulty of charging status remotely. It is convenient for citizens to travel and has high service added value.

\section{Appendix}

1. Fan Wenting, Ma Jingnan, Li Ying, Zhao Wei, Cao $\mathrm{Na}$. Intelligent planning of electric vehicle charging station [J/OL]. Inner Mongolia Power Technology: 1-6 [2019-06-16].

2. Zhang Wei. Research on electric vehicle charging demand identification and charging facility layout method based on traffic [A]. China Association of Science and Technology, Ministry of Transport of the People's Republic of China, China Academy of Engineering. 2019 World Transportation Conference Proceedings [C]. China Science and Technology Association, Ministry of Transport of the People's Republic of China, Chinese Academy of Engineering: China Highway Society, 2019:6.

3. Zhang Xian, Wang Jie, Yang Qingxin, Wei Bin, Wang Songqi. Research on power coupling mechanism and switching control of dynamic wireless power supply system for electric vehicles [J/OL]. Transactions of Electrotechnical Engine- 
ering: 1-9[2019-06-16].

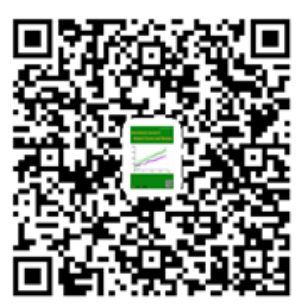

